efforts on the part of the officers of both the vestry and the guardians.

Drs. Greenwood and Carter spared no exertion; the greatest praise is due to their energy in vaccination, and in paying so many professional visits to persons suffering, or supposed to be suffering, from the malady. The gentlemen named practically lived at the dispensary for about a fortnight.

The most important lesson is, that by a combination of all the means mentioned, an outburst of small-pox, which, from the number attacked, threatened to spread from Portland Town through the parish, and it might be thence through the whole metropolis, can be kept within bounds.

Finally, in these days, when centralised bodies are attempting to take away local government from local authorities, it is well to put on record that the Vestry and the Board of Guardians, without delay and with absolute unanimity, voted the necessary money to meet any expenditure that might be necessary.

I desire to express my great appreciation of the way in which the sanitary inspectors (Messrs. Gorniot, Perry, Phillips, and Yeo) carried out their duties on this occasion; they worked fearlessly and well from early in the morning until late at nigbt.

\section{REPORT UPON AN OUTBREAK OF SMALL-POX IN THE MALDON RURAL SANITARY DISTRICT.*}

By J. C. THRESH, D.SC., M.B, M.O.H. for the Maldon Rural Sanitary Districts.

ON the morning of Friday, June $29 t h$, I was summoned by a telegram to see a suspected case of small-pox at Langford Place, the country seat of the Right Hon, Lord Byron. The patient, Alice Hedge, was a young maidservant who had been taken ill on the 25 th, and had developed a papular rash on the $28 \mathrm{tb}$. The nature of the case admitted of no doubt, and the investigation of its origin revealed the following facts.

Joseph Moss, a crippled agricultural labourer, aged 68 , residing in the village of Langford, was taken ill on June $r 3^{\text {th }}$, he complained chiefly of lassitude and pain in his foot, the pain being attributed to an inflamed bunion. On the 15 th he felt much worse and had to be carried to bed. The foot assumed a blue colour from the extravasation of blood, and a medical man was sent for. There was some elevation of temperature, and the medical attendant advised that no one should be allowed to see him until the nature of the disease was more manifest. The discoloration extending to the leg, "blood poisoning" was diagnosed, and

* Special Report submitted to the Rural Sanitary Authority by Dr. Thresh, M.O.H., July 31st, 1894. as the man got worse his friends and relatives were allowed to visit him. Purpuric spots appeared on the dependent parts, spread rapidly, and the patient died on the morning of the 19 th. Two women laid out the body, and the same night an undertaker and assistant placed it in a coffin, but the lid was not fastened down until the day before the funeral, the and.

The girl Alice Hedge was a granddaughter of the man Moss, and had visited him during his illness. That he had died of small-pox I had no doubt, and I immediately made a list of all the persons who had seen him during his illness and after his death, and visited all within reach forthwith. At the house itself $I$ found an unmarried daughter, Emma Moss, aged $3 I$, feverish, and complaining of pains in the back and head. A short distance away at a married daughter's, I found Edward Hedge, aged 35, laid on the bed, complaining of the same symptoms. His wife also said that she felt ill, and a lodger came in saying that he had not strength to do his work. At Woodham Walter, another married daughter, Susannah Wordley, aged 37 , was also laid on the bed too ill to rise. The other people visited were at that time (June 29 th) apparently in good health. We had, therefore, one well marked case, and five others exhibiting premonitory symptoms of the disease. I ascertained that there was in Langford Park an unoccupied farmhouse belonging to Lord Byron, and permission was obtained to use this as a temporary hospital. By noon of the following day it was furnished, and during the afternoon I obtained two nurses, an assistant-nurse, and a man with an extemporised ambulance. By six p.m. five of the patients had been moved into the hospital. All of them now were found to be unmistakably suffering from small-pox. The sixth case was moved on the following (Sunday) morning. Next day, Mary Ann Little, aged 58, a woman residing in Ulting, who had helped to lay out the body of the deceased man, was attacked, and was at once removed. On the same day Joshua Freeman, aged 35 , a man who had assisted to place the body in the coffin, was found to have a few wellmarked spots upon the face, and then acknowledged that he had been feeling ill for two or three days, a fact which he had previously suppressed. As my farmhouse was full I had him removed to a temporary wooden hospital which the Maldon Urban Authority had constructed to accommodate some patients suffering from the same disease. On July znd, Austin Hedge, aged 35, a resident of Heybridge, was complaining of illness, but until the eruption appeared on the $4^{\text {th }}$ he would not believe that he had small-pox or submit to removal. He also was taken to the Maldon shed. This man had visited Moss during his last illness to pray with him. On the same day I also removed the undertaker, William Last, aged 40 , an inhabitant of Heybridge. 
He had been ailing two or three days, but would not give up work. There were signs of papulation on the face, but no distinct papules. The rash never passed beyond this stage, and the man died on the 6th of variola nigra. On August 6th Emma Moss, a daughter-in-law of Joseph Moss, was taken ill with all the premonitory symptoms of smallpox. She had been revaccinated on the Ist, and the vaccination appeared to be most successful. By the 8th inst. she was so much better, and, no papules appearing, I decided not to remove her. Her husband had refused to be revaccinated, and on the 8 th he was taken ill, and on the roth removed to the Maldon sheds.

A daughter of the first sufferer, residing at Canning Town, was communicated with. I learnt that she had been successfully revaccinated about seven years ago, and had not been attacked. A son residing at Hampton Wick was also written to ; but on July 4 th a letter was received from his wife saying that he had been removed to hospitalsuffering from small-pox. $\mathrm{He}$ had been revaccinated at the same time as his sister Alice, seven years ago, but in his case the revaccination was unsuccessful. All the before-mentioned persons had visited Joseph Moss during his last illness or seen his body after death.

The only other persons who had been near the original case was a woman who laid out the body; she had been successfully revaccinated many years ago, and she escaped infection.

The last case was removed on July roth, and as the only case which has occurred since is that of a nurse in the temporary hospital, we may fairly conclude that the steps taken to stamp out the disease were completely successful.

Doubtless the most important step taken to arrest the spread of the disease was the prompt furnishing of the old farmhouse and the removal of the patients the instant the diagnosis of smallpox was certain. The next in importance was the revaccination of all members of the farnilies, any member of which had been exposed to infection. Not only was the public vaccinator set to work, but the other medical men called upon the families whom they usually attended, and persuaded as many as possible to be revaccinated. In this way in a few days nearly every person in the least degree likely to have been infected was revaccinated. The only exception was John Moss, of Mundon. His wife was revaccinated on July Ist, and had a doubtful attack; but he refused to submit to the operation, and afterwards suffered from a severe form of the disease. Some of the pustules became hæmorrhagic, and a few purpuric spots appeared on the hands and feet. For some days his life was in danger, but he is now rapidly recovering.

When the patients were removed, their clothing, bed, and bedding were also taken to the temporary hospital, and some burnt and others disin- fected. A man and woman from the hospital then went to the house, disinfected, lime-washed, and cleaned down generally. The patients who died were at once wrapped in sheets soaked in carbolic acid, placed in a coffin with a quantity of carbolized lime, and buried within twenty hours. The three nurses and man were revaccinated as soon as they came to the hospital. The washerwoman having been revaccinated and having had small-pox was not again vaccinated. As only one of the four vaccinations was successful, on July $4^{\text {th }}$ it was repeated. This time two others were successful, but one nurse appeared to be immune. On July I $5^{\text {th }}$ she complained of feeling ill, and a day or two later about six papules appeared-one on the tip of the nose, three on the upper lip, and two on the chest. I kept her in bed a couple of days, but as she then felt quite well I allowed her to resume her duties.

Remarks.-The Rural Sanitary Authority possesses no permanent isolation hospital. It, however, has a tent capable of accommodating four patients. At the time this outbreak occurred the tent was being used by the Maldon Urban Authority, to whom it had been lent by the chairman and clerk of the Rural Sanitary Authority without consulting me. The Urban Sanitary Authority had, however, given an undertaking that should the disease spread into our district they would purchase for us a tent. This would have caused us to run a serious risk on account of the delay, but, fortunately, we were able to secure the farm house, and as I reported that there would probably be more cases than this house would accommodate, and as the tent was full and other cases were occurring in the town, the Urban Sanitary Authority promptly erected a large wooden shed to accommodate twelve patients and nurses. This was afterwards used jointly by the two Authorities.

How Joseph Moss became infected with smallpox I have been unable to ascertain, although I have made every possible inquiry. There were three or four cases in Maldon Borough at the time, but Moss lived two miles away, and he certainly had never been half a mile from his home for many months. No person from the infected families had been in Langford. A number of strangers were in the parish at the time as the peapicking was commencing, but I could hear of no suspicious case amongst these people. Of those who visited the man Moss, the widow and the daughter from London, who had been successfully revaccinated, and Mrs. Wass, who laid out the body and who also had been successfully revaccinated, alone escaped. All the others, including the undertaker and his assistant and a woman who helped to lay out the body, became infected, and suffered more or less severely. Two, a daughter and the undertaker, contracted the same form of the disease as that from which the man 
had died, and they also succumbed. But for our prompt action in removing all infected persons, there is little doubt that many more cases would have occurred.

In many instances the incubation period of the disease could be very approximately ascertained, and the results are interesting.

\begin{tabular}{|c|c|c|c|}
\hline & & & \\
\hline $\begin{array}{l}\text { Alice Hedge... } \\
\text { Edward Hedge and }\end{array}$ & & 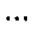 & .. 6 to 8 days. \\
\hline Ezekial Wordley & $\ldots$ & $\begin{array}{l}\cdots \\
\ldots\end{array}$ & ... Io days. \\
\hline Susan Wordley & $\cdots$ & $\ldots$ & ... Io to I2 days. \\
\hline Joshua Freemán & $\cdot$ & $\ldots$ & .. 8 days. \\
\hline Austin Hedge & $\ldots$ & $\ldots$ & ... 12 or 13 days. \\
\hline William Last... & $\ldots$ & $\ldots$ & ... II or 13 days. \\
\hline Mrs. Joha Moss & $\ldots$ & $\ldots$ & ... 19 or 20 days. \\
\hline John Moss ... & $\cdots$ & $\ldots$ & ... 19 or 22 days. \\
\hline
\end{tabular}

The variation is greater than is usually recognised. On the one hand, there is no doubt that two of the persons were taken ill within eight days of visiting Joseph Moss; and on the other, two were not taken ill until at least nineteen days after. I made special inquiries as to the possible explanation of these long incubation periods. I found that the widow had given John Moss a pair of her late husband's trousers, and that he wore

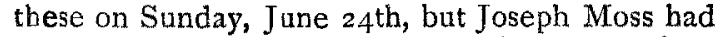
not worn these for some time, as they were a best pair, reserved for special occasions. They, however, had been hung up in the room in which the man died. The widow had asserted that no clothing had been given away or sent out of the bouse, but explains her forgetfulness by her distress at losing her husband, and finding so many of her relatives and friends were being taken ill. In my opinion, John Moss was much more likely to have been infected when visiting his father than by wearing the trousers. The incubation period in the case of his wife was also long, nineteen to twenty days; but the medical attendant is inclined to think that the severe symptoms from which she suffered were the effect of the revaccination. Several persons who were revaccinated exhibited similar but less marked symptoms; and although it is possible that she also was affected by the vaccination, I am of opinion that she had an abortive form of small-pox, due to the vaccine virus overtaking in its action the small-pox poison received thirteen or fourteen days earlier. I am also convinced that had John Moss submitted to revaccination, he would either have escaped entirely, or merely have been affected in a similar manner to his wife.

In conclusion, I have only to report that these outbreaks in the Maldon urban and rural sanitary districts have caused the two Authorities to decide upon combining for the purpose of acquiring one or more permanent bospitals. The conditions have already been agreed upon by a joint committee, and are now awaiting confirmation by the respective Authorities.

\section{SYPHILIS IN THE INNOCENT *}

SyphiLIs, as a non-venereally acquired disease has been the subject of numerous communications in medical journals, but it has never previously been honoured by a large volume of four hundred pages. We are not surprised to learn that the volume is the result of ten years' work devoted to this aspect of the study of syphilis.

The work contains a classification of the methods of infection in Syphilis insontium, by over one hundred categories of transmission, according as it occurs (I) in connection with household and industrial life; (2) in the case of children; (3) in professional pursuits.

From a classification of 7,123 cases, it appears that the genital and perigenital chancres were 6,770 , the extra-genital chancres, 353 .

In another table we learn that out of 9,058 extra-genital chancres, 1,8 Io occurred on the lips, I, 148 on the breast and nipple, 734 in the buccal cavity, 462 on the fingers and hand, 372 on the eyelids and conjunctiva, 307 on the tonsils, 264 in the throat, 157 on the tongue, 146 on the chin, 145 on the cheek, and smaller numbers on the other parts of the body. Out of the same total 1,863 were apparently caused by vaccination, 745 by cupping and phlebotomy, 79 by circumcision, and 82 by tattooing.

Between pages I $_{5}$ and 124 is a tabular chronological arrang ement, as complete as practicable, of the epidemics of innocent syphilis which have occurred from the year $\times 577$ to the present time. This contains data relating to over roo epidemics, great and small, affecting over 3,000 victims. Many of these were due to wet cupping or to breastdrawing. In one outbreak in France, A. D. 1727 , a midwife who first infected berself digitally, transmitted the disease to 50 parturient women, and through them to 30 or more in their families. Apparently the first series of cases of syphilis traced to circumcision was at Krakau in Poland, A.D. 1805 . In this outbreak it was discovered that the psylle or mohel had syphilides in the mouth.

Vaccination unfortunately figures among the causes of epidemics of innocent syphilis. The first authentic cases were found at Udine in Austrian Lombardy in the year 1814 . The vaccinifer bad inherited syphilis, and out of 40 vaccinated from this source nearly all were said to have been infected. In $\mathrm{I} 862$ an outbreak of vaccinal syphilis is described by Otterson in the Union army during the Civil War. Three hundred were vaccinated, of which only 80 succeeded, and most of the 80 were directly infected. Jonathan Hutchinson's two epidemics, in which $I I$ and Io respectively were infected, are probably better known than the above.

* "Syphilis in the Innocent (Syflitis insontiun) clinically and historically considered, with a Pian for the Legal Control of the Disease," By L. Duncan Bulkley, A.M., M.D. (New York: Bailey and Fairchild, 29, Park Row.) 